\title{
Increasing Inpatient Consultation: Hospitalist Perceptions and Objective Findings. In Reference to: "Hospitalist Perspective of Interactions with Medicine Subspecialty Consult Services"
}

\author{
Marika Kachman, BA ${ }^{1 *}$, Keme Carter, MD², Shannon Martin, MD, MS 3
}

\begin{abstract}
'University of Chicago Pritzker School of Medicine, Chicago, Illinois; ${ }^{2}$ University of Chicago, Section of Emergency Medicine, Chicago, Illinois; ${ }^{3}$ Department of Medicine, University of Chicago, Chicago, Illinois.
\end{abstract}

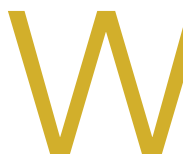

e read with interest the article, "Hospitalist Perspective of Interactions with Medicine Subspecialty Consult Services." ${ }^{1}$ We applaud the authors for their work, but were surprised by the authors' findings of hospitalist perceptions of consultation utilization. The authors reported that more hospitalists felt that their personal use of consultation was increasing (38.5\%) versus those who reported that use was decreasing (30.3\%). ${ }^{1}$ The lack of true consensus on this issue may hint at significant variability in hospitalist use of inpatient consultation. We examined consultation use in 4,023 general medicine admissions to the University of Chicago from 2011 to 2015. Consultation use varied widely, with a 3.5-fold difference between the lowest and the

*Address for correspondence: Marika Kachman, BA, 5307 South Hyde Park Blvd \#801, Chicago, IL 60615; Telephone: (202) 446-7959; Fax: (773) 795-7398;

E-mail:mkachman@uchicago.edu

Received: March 2, 2018; Accepted: March 24, 2018

@2018 Society of Hospital Medicine DOI 10.12788/jhm.2992 highest quartiles of use $(P<.01) .^{2}$ Contrary to the survey findings, we found that the number of consultations per admission actually decreased with each year in our sample. ${ }^{2}$ In addition, a particularly interesting effect was observed in hospitalists; in multivariate regression, hospitalists on nonteaching services ordered more consultations than those on teaching services. ${ }^{2}$ These findings suggest a gap between hospitalist self-reported perceptions of consultation use and actual use, which is important to understand, and highlight the need for further characterization of factors driving the use of this valuable resource.

Disclosures: The authors have no conflicts of interest to disclose.

\section{References}

1. Adams TN, Bonsall J, Hunt $\mathrm{D}$, et al. Hospitalist perspective of interactions with medicine subspecialty consult services. J Hosp Med. 2018:13(5):318323. doi: 10.12788/jhm.2882.

2. Kachman M, Carter K, Martin S, et al. Describing variability of inpatient consultation practices on general medicine services: patient, admission and physician-level factors. Abstract from: Hospital Medicine 2018; April 8-11, 2018; Orlando, Florida. 